\title{
Hospedaria de Imigrantes da Ilha das Flores: Um Lugar, Muitas Histórias
}

\author{
Immigrant Hostel of Flores Island: One place, many stories \\ Natália de lima Azevedo ${ }^{1}$ \\ 1 Bolsista de extensão. Universidade do Estado do Rio de Janeiro (UERJ), Brasil. E-mail: I_natalia15@hotmail.com
}

Recebido em: 04/02/2015 | Aprovado em: 07/05/2015

DOI: 10.12957/interag.2016.23575

\begin{abstract}
Resumo
A Hospedaria de Imigrantes da Ilha das Flores tinha como objetivo a recepção, o acolhimento e a triagem da grande leva de imigrantes que chegavam ao Brasil. Este texto pretende destacar brevemente a história da Hospedaria de Imigrantes da Ilha das Flores, relatando o papel desempenhado por ela em seus anos de funcionamento. Pretende também situar a criação do Centro de Memória da Imigração da Ilha das Flores e o processo de pesquisa para reconstruir as memórias deste local. A pesquisa foi feita através do uso de periódicos, relatórios ministeriais e diversos outros documentos que nos permitem compreender como se constituiu a história deste local. Coordenador, bolsistas e outros pesquisadores participam do processo de pesquisa que tem seus resultados compartilhados através reuniões periódicas. O Museu a Céu Aberto é produto das pesquisas e das nossas experiências adquiridas no processo de mediação, através dele reproduzimos o que apreendemos possibilitandonos retirar a Hospedaria de Imigrantes do lugar do desconhecido para o lugar das descobertas.
\end{abstract}

Palavras-chave: imigração, Hospedaria de imigrantes, Centro de Memórias.

\begin{abstract}
The Immigrant Hostel of Flores Island aimed at receiving and screening the many immigrants who were arriving in Brazil. This text aims at briefly highlighting the history of Immigrant Hostel of Flores Island, reporting the role it played in the years of its operation. It also seeks to situate the creation of the Flores Island Immigration Memory Center and the research process of reconstruction of the memories of this place. The research was conducted through the use of periodicals, ministerial reports and many other documents that have allowed us to understand how the history of this place was built. Coordinator, research fellows and other researchers participated in the process that has shared results in regular meetings. The open-air museum is the product of research and our experiences in the mediation process. Through it, we reproduce what we have learnt, enabling us to remove the Immigrant Hostel from an unknown place to the place of discovery.
\end{abstract}

Keywords: Immigration, Hostel for immigrants, Memory Center.

Área temática: Cultura.

Linha de extensão: Patrimônio cultural, Histórico e Natural.

\section{Introdução}

Milhares de pessoas passam todos os dias pela BR-101, no trecho que liga as cidades de São Gonçalo e Niterói, e nem sempre percebem a Base Naval da Ilha das Flores, ou sequer imaginam o que já aconteceu naquele lugar. A caminho do trabalho ou de casa, 
não sabem que ali já foi uma ilha ou que abrigou a primeira Hospedaria de Imigrantes do Brasil. A Ilha das Flores ocupa o lugar do desconhecido para a maior parte das pessoas, que ignoram as histórias que podem ser contadas a partir dali.

A Hospedaria de Imigrantes da Ilha das Flores tinha como objetivo a recepção, o acolhimento e a triagem da grande leva de imigrantes que chegavam ao Brasil. Foi criada em 1883, pelo Governo Imperial brasileiro, num momento em que a Europa vivia um período de desenvolvimento do capitalismo, acentuado aumento da população rural e forte depressão agrícola, fatores que levaram milhares de pessoas a migrarem para as Américas. No Brasil, o momento era de transição da mão de obra escrava para a livre e o imigrante teria um papel fundamental neste processo.

Ali eram registrados e por cerca de oito dias se alimentavam, se hospedavam e recebiam cuidados médicos. Entretanto, durante o período de funcionamento da Hospedaria houve alguns casos específicos em que as pessoas permaneceram por mais tempo. A Hospedaria para esses imigrantes era o local do primeiro contato com o Brasil, com a língua, com a comida, com as pessoas e com os cheiros antes de iniciarem uma nova vida no país.

Não somente imigrantes foram recebidos na Ilha. Também os migrantes, especialmente, os nordestinos, desde pelo menos o final do século XIX, prisioneiros de guerra e presos políticos. O local foi marcado por diversos tipos de relações onde diferentes histórias podiam se cruzar.

O projeto de extensão "Centro de Memória da Imigração da Ilha das Flores" busca sensibilizar a sociedade acerca dos dramas vivenciados nos deslocamentos migratórios internacionais e internos. Através da pesquisa em periódicos, relatórios ministeriais e diversos outros documentos busca-se entender como se constituiu a Hospedaria de Imigrantes em seu período de funcionamento entre 1883 e 1966. O coordenador, bolsistas e outros pesquisadores participam do processo de pesquisa e compartilham os resultados através de reuniões periódicas. Esses momentos são importantes, pois é através deles que exercitamos o fazer do historiador na busca dos vestígios para a construção da história da Hospedaria. 
Outra fase que podemos destacar nesse processo é a investigação através da história oral. Contamos hoje com um banco de 34 entrevistas, dentre as quais se encontram imigrantes, migrantes e ex-funcionários que, em algum momento de suas vidas, viram sua história se entrelaçar com a da Hospedaria da Ilha das Flores. As entrevistas se somam ao quadro de fontes já existentes como os Relatórios Ministeriais, livros de registro, periódicos, fotografias entre outros. O cruzamento dessas fontes nos possibilita estabelecer uma melhor compreensão do passado daquele local.

A culminância do trabalho realizado pelos bolsistas neste projeto é a transmissão do conhecimento já reunido através das mediações no Museu a Céu Aberto da Ilha das Flores. Nesse momento, temos a oportunidade de lidar com um público bastante diversificado: alunos de diversos segmentos, pesquisadores, descendentes de imigrantes moradores de São Gonçalo e cidades vizinhas, dentre outros. O visitante, logo que chega à Ilha, se depara com um lugar muito bonito e a primeira curiosidade que surge é: por que Ilha das Flores? E é a partir desta questão que iniciamos a mediação. O que ocorre durante a visita e a mediação é uma troca de conhecimentos que possibilita uma mudança na forma de olhar a Ilha das Flores.

Muitas questões são levantadas durante a realização do roteiro de visita, que vão permitindo ao visitante imaginar como seria a hospedaria e sua importância nos seus diferentes momentos de funcionamento. A surpresa, o encantamento e a produção de conhecimento são vivenciados tanto por quem está visitando a Ilha das Flores quanto pelos bolsistas/mediadores. No contato com os adultos e o público escolar, exercitamos uma prática pedagógica fora da sala de aula e amadurecemos na condição de futuros professores de história.

O Museu a Céu Aberto é produto das pesquisas e das nossas experiências no processo de mediação; através dele reproduzimos o que apreendemos possibilitando-nos retirar a Hospedaria de Imigrantes do lugar do desconhecido para o lugar das descobertas.

\section{A Hospedaria de imigrantes da Ilha das Flores}

A Hospedaria, criada em 1883, é fruto de uma política do governo para estimular a vinda da mão de obra imigrante e de uma preocupação com as doenças que assolavam a Corte Imperial. A necessidade de se pensar em uma forma de receber o imigrante não 
foi algo exclusivo do Brasil. Em todo o continente americano, nos países que receberam grandes levas de imigrantes, foram criados dispositivos para receber estrangeiros.

A cidade do Rio de Janeiro, ao longo do século XIX, foi marcada por muitas epidemias que atingiram mais da metade da população, deixando um saldo de muitos mortos. Dentre as doenças que assolaram a cidade estavam a febre-amarela, a cólera-morbus, a varíola e a tuberculose. Tal situação levou a Europa a realizar campanhas antiimigratórias para o Brasil.

Não existiam hospedarias oficiais; as utilizadas eram particulares, subsidiadas pelo governo, mas a situação de salubridade nem sempre era adequada. A preocupação e a busca por uma melhor forma de receber o imigrante, juntamente com o interesse de se fomentar a imigração, levaram ao início das negociações para a compra da Ilha. Neste momento, a Ilha pertencia ao Conselheiro e Senador do Império José Ignácio Silveira da Motta. O político desenvolvia na Ilha a produção de alguns gêneros agrícolas e a criação de peixes em seis tanques que comportavam até doze mil unidades. A partir de uma visita da comissão do Imperial Instituto Fluminense de Agricultura, em 1876, para avaliar a experiência da piscicultura, foi produzido um relatório e despertou-se o interesse do Governo Imperial pelo espaço. As negociações foram concluídas no início de $1883 .^{1}$

Em 1876, a Inspetoria Geral de Terras e Colonização é criada, sendo responsável por cuidar do imigrante desde a entrada até sua instalação nos locais de destino. A preocupação de proteger a mão de obra imigrante, tão importante neste momento, vai levar o governo a ver a Ilha das Flores como o melhor local para instalar sua Hospedaria.

A Hospedaria, na sua inauguração, era composta por um grande galpão dividido em consultório médico, salas para enfermarias, salões para dormitório e compartimentos para o serviço administrativo. Apresentava um quadro de funcionários que contava com médico, intérprete, farmacêutico, escrivão, maquinista, dentre outros, para o atendimento aos imigrantes.

Era destinado à Hospedaria todo passageiro de terceira classe que chegasse em navios vindos da Europa. Ao chegar ao porto do Rio de Janeiro, os navios podiam passar por 
uma inspeção médica, e, caso tivesse algum passageiro doente a bordo o mesmo seria encaminhado para hospitais próximos como o Hospital Paula Candido (que ficava em Niterói). Os imigrantes eram transferidos para batelões que faziam o transporte para a Ilha das Flores e ao desembarcarem era feito o registro; em seguida, passavam por uma inspeção médica e, por fim, eram direcionados aos alojamentos ou demais locais da Ilha.

O imigrante permanecia na maioria dos casos por oito dias. Neste período, eles tinham acesso a um balcão de empregos onde fazendeiros buscavam mão de obra, ou já vinham com o destino acertado. Assim que definiam seu destino deixavam a Hospedaria.

Passaram pela Hospedaria diversas nacionalidades como a portuguesa, italiana, alemã, espanhola entre outras. O fluxo durante o seu funcionamento era variável, contando com períodos de maior ou menor movimento. A Hospedaria passou por diversas melhorias em sua infraestrutura para adequar o espaço para o atendimento ao imigrante; houve, por exemplo, a ampliação de sua capacidade de 1000 pessoas para 3000 pessoas.

A hospedaria de imigrantes da Ilha das Flores não recebeu apenas imigrantes durante o seu período de funcionamento, mas teve outros usos ${ }^{2}$ principalmente em períodos em que o fluxo imigratório era menor.

Desde o fim da década de 1880 , a Ilha passou a receber migrantes, em sua maioria, nordestinos. O governo utilizou a Ilha como um dos mecanismos para atender esse grupo nos períodos marcados por grandes secas. Os chamados "flagelados da seca" eram levados para a hospedaria de onde depois eram encaminhados a postos de trabalho em outras regiões do país.

A Hospedaria foi utilizada como presídio militar em diversos momentos da sua história. Em 1917 foi transferida para os cuidados da Marinha do Brasil e, pela primeira vez, usada como presídio recolhendo tripulantes de navios alemães. Outro momento foi durante o governo de Arthur Bernardes onde foram enviados para a ilha os anarquistas e pessoas que se opunham ao Governo.

Durante a década de 1930, a Ilha voltou a ser utilizada como presídio em dois momentos: primeiro em 1932, na Revolução Constitucionalista, quando recebeu 3780 
combatentes, os prisioneiros Paulistas. Em 1935, a Ilha das Flores volta a ser presídio e recebe prisioneiros da Revolta Comunista. Cabe salientar que durante os períodos de presídio militar a Hospedaria de Imigrantes não deixou de exercer sua função principal que era a de receber imigrantes. Entretanto, nesses períodos, o fluxo de imigrantes para a Ilha era menor e seu espaço ocioso era utilizado para outros fins.

Na década de 1940, marcada pelos conflitos da Segunda Guerra Mundial, a Ilha das Flores serviu como clausura para os chamados "Súditos do Eixo" (alemães, italianos e japoneses). Posteriormente, acolheu os refugiados de guerra encaminhados pela Organização Internacional para Refugiados, pessoas deslocadas que não queriam ou não podiam voltar para seus países de origem. O Brasil via nessas pessoas uma mão de obra em potencial, que neste momento não seriam apenas agricultores, mas também uma força de trabalho mais especializada.

Outros usos foram sendo feitos da Hospedaria ao longo de sua história, como o recebimento de grupos diversos, pessoas "sem trabalho" em busca de ajuda e dos alunos dos patronatos agrícolas. Houve inclusive discussões sobre o que fazer com aquele espaço que ficava ocioso nos períodos de diminuição do fluxo de imigrantes para o país. É possível observar que a história desse local foi sendo moldada conforme as necessidades e momentos específicos vivenciados no país.

Com o fim das atividades da Hospedaria em 1966, a Ilha Das Flores viria a ser utilizada ao final de 1968 como um presídio destinado aos opositores do Regime Militar, instaurado após o golpe civil militar de 1964 em que o presídio utilizou as antigas instalações da Hospedaria.

A Ilha das Flores atualmente sedia a Tropa de Reforço do Corpo de Fuzileiros Navais da Marinha do Brasil e, em 2010, foi firmado um convênio entre esta instituição e Universidade do Estado do Rio de Janeiro (UERJ) para a criação do Centro de Memória da Imigração da Ilha das Flores.

\section{Centro de Memória da Imigração da Ilha das Flores}

Com o fim da Hospedaria de imigrantes da Ilha das Flores em 1966, o espaço da Ilha passou para o Ministério da Marinha, que fixou o Comando da Tropa de Reforço do 
Corpo de Fuzileiros Navais. Neste momento de transição, o acervo da Hospedaria se perdeu. ${ }^{3}$ No acervo estariam documentos que registravam as atividades cotidianas, como relatórios administrativos e fichas de funcionários. Mesmo tendo desempenhado um papel importante durante os anos em que funcionou, sua história é pouco conhecida.

O Centro de Memória se coloca no lugar de encontrar os vestígios da Hospedaria de Imigrantes e, para isso, recorreu aos documentos que pudessem conter informações que levassem à compreensão da história da instituição. Dentre os documentos utilizados na pesquisa estão os livros de registro de imigrantes da Hospedaria, sob a guarda do Arquivo Nacional, os Relatórios Ministeriais e os periódicos disponíveis no site da Hemeroteca Digital da Biblioteca Nacional.

Todos esses documentos apresentados são estudados pelos integrantes do projeto. Cada bolsista fica responsável por uma parte da pesquisa e, a partir da orientação do coordenador, é dividido entre os integrantes um período da ilha para pesquisa, onde deve ser feito um mapeamento em todo material disponível que vai culminar em relatórios técnicos, contendo todas as informações encontradas nos períodos pesquisados.

Feitos os relatórios técnicos de todas as fontes, cruzamos as informações para podermos sistematizá-las em relatórios temáticos onde selecionamos os principais temas sobre a Hospedaria. Hoje contamos com um banco de dados riquíssimo e já conseguimos, por exemplo, mapear quase todo o período de funcionamento da Hospedaria no site da Hemeroteca Digital. As notícias sobre a Hospedaria presentes na Hemeroteca nos permitem uma compreensão acerca das discussões sobre os usos do espaço, recepção dos imigrantes e aspectos do funcionamento da Hospedaria.

Todo o processo de pesquisa possibilitou a organização de um acervo sobre a Hospedaria de imigrantes da Ilha das Flores, que ainda está em construção, e uma forma de divulgar o material já sistematizado é através do site: http://www.hospedariailhadasflores.com.br/historico.asp. No site é possível encontrar um breve histórico sobre a instituição, biografias de imigrantes que passaram pela Ilha, 
galeria de fotos. Hoje contamos com duas coleções disponíveis no site e mais duas sendo preparadas. E ainda é possível agendar as visitas ao Museu a Céu Aberto.

\section{Museu a Céu Aberto}

Em Novembro de 2012 é inaugurado o Museu a Céu Aberto para visitação do público. Durante a visita é possível conhecer as construções da antiga Hospedaria de Imigrantes, que ainda se mantêm em parte preservadas, bem como as principais características da paisagem local.

A visita é organizada a partir de cinco totens explicativos espalhados em lugares estratégicos da Ilha. ${ }^{4}$ A mediação é feita pelos bolsistas que a iniciam apresentando uma maquete da Hospedaria e um vídeo que tenta construir o olhar do visitante para o fato de que aquele local já foi uma Ilha. Na década de 1980, a Ilha das Flores e a Ilha do Carvalho foram unidas ao continente no processo de aterramento da região para a construção do trecho da BR-101 que corta o município de São Gonçalo. Procuramos também demonstrar o processo de alterações, principalmente em relação às construções, em diferentes tempos.

Esse primeiro momento é interessante principalmente quando recebemos a visita de crianças que conseguem no decorrer da visita identificar claramente os espaços que lhes são apresentados e o primeiro local que elas identificam é o "Cais do Bote", onde a maquete e o vídeo são apresentados.

Durante o circuito museológico procura-se retirar a Hospedaria do lugar do desconhecido e construir junto com o visitante um olhar para as experiências vividas naquele lugar, principalmente as dos imigrantes que chegavam ao país com o sonho de construir uma nova vida. Neste momento, surgem vários tipos de questionamentos que nem sempre são fáceis de responder. As perguntas das crianças quase sempre são as mais interessantes, deixando-nos muitas vezes surpresos. Por se tratar de um momento de troca de conhecimento é uma excelente oportunidade para levar o público à reflexão.

Recebemos grupos variados de visitantes, famílias que buscam um passeio cultural aos fins de semana, descendentes de imigrantes/migrantes que buscam ali sua própria história, pesquisadores e, por fim, estudantes do ensino básico e universitário que se 
configuram no nosso maior público. A presença de um público variado faz com que durante as mediações tenhamos de nos adequar ${ }^{5}$ ao nosso ouvinte. Afinal, como falar de imigração para crianças de cinco anos de uma creche? A partir das nossas vivências vamos construindo estratégias a serem usadas durante o circuito do museu.

Em relação às visitas escolares foi feito um trabalho de divulgação do Museu junto aos professores das redes municipais dos municípios do entorno como Niterói, São Gonçalo e Itaboraí o que acarretou em um aumento significativo do número de visitas.

No ano de 2014, foi realizado um dia de atividades junto aos professores de história e geografia da rede Municipal de Niterói. A proposta era a de apresentar aos professores formas de se trabalhar com o tema da imigração dentro da sala. Para atingir tal objetivo, primeiramente os participantes realizaram o circuito pela Ilha para que, depois, no espaço que hoje é a nossa sede, a antiga "Casa do Intérprete", realizassem atividades, preparadas pelos bolsistas, que enfocavam diferentes períodos da imigração no país e se utilizavam de diferentes tipos documentais.

O Centro de Memória no espaço do museu, ainda no ano de 2014, recebeu a exposição “Olhares sobre São Gonçalo” do artista local Paulo Nunes. A exposição foi inaugurada na semana comemorativa dos 124 anos da cidade e contava com quadros e esculturas que representavam lugares importantes da cidade e algumas personalidades significativas do município. Quem visitava o museu tinha também a oportunidade de conhecer a exposição.

O Museu a Céu Aberto participou da XII Semana de museus em 2014. O público presente neste dia além de fazer o circuito do Museu pode dialogar com imigrantes e antigos funcionários da Hospedaria: conhecer as motivações dos imigrantes na década de 1950 e como funcionava o espaço, a partir de conversa com quem vivenciou aquela situação.

O Museu já sediou em seu espaço o Seminário internacional Pontes sobre o Atlântico e o Seminário Internacional “Hospedarias de Imigrantes” Ilha das Flores (RJ), Brás (SP) e Buenos Aires (Argentina), ambos realizados no fim de 2013. 
Entendemos o museu como espaço de produção de saber e preservação do patrimônio, além de exercer ampla responsabilidade social ${ }^{6}$. O Centro de Memória da Imigração da Ilha das Flores enquanto projeto de extensão tenta cumprir seu papel não só na pesquisa, mas seu papel educativo e o de beneficiar não só as cidades vizinhas, mas todos aqueles que desejam conhecer mais sobre imigração e descobrir as tantas histórias que podem ser contadas através da Hospedara de Imigrantes. Para os estudantes (bolsistas) envolvidos no projeto, temos a possibilidade de desenvolver a pesquisa, mas também de adquirir conhecimento e experiências muito interessantes através do processo de mediação no Museu.

\section{Referências}

1. REZNIK, Luís; FERNANDES, Rui Aniceto Nascimento. Hospedarias de Imigrantes nas Américas: a criação da hospedaria da Ilha das Flores. História (São Paulo) v.33, n.1, p. 234253, jan./jun. 2014 ISSN 1980-4369 234.

2. REZNIK, Luís; FERNANDES, Rui Aniceto Nascimento; SILVA, Henrique Mendonça da. A Hospedaria de Imigrantes da Ilha das Flores: história e memória. In: José Jobson de Andrade Arruda; Vera Lúcia Amaral Ferlini; Maria Izilda Santos de Matos; Fernando de Souza. (Org.). De colonos a imigrantes: i(e)migração portuguesa para o Brasil. São Paulo: Alameda, 2013, v., p. 367-382.

3. REZNIK, Luís; FERNANDES, Rui Aniceto Nascimento. Imigração: documentação, política e história. In: Hugo Cancino; Rogelio de la Mora; Lená Medeiros de Menezes; Silvano Benito Moya. (Org.). Miradas desde la Historia social y la Historia intelectual. America Latina en sus culturas: de los procesos independistas a la globalización. 1ed. Córdoba, Argentina: Centro de Estudios Históricos Prof. Carlos Segreti, 2012, v., p. $213-224$.

4. COSTA, Julianna Carolina Oliveira; SILVA, Henrique Mendonça da; NASCIMENTO, Thiago Rodrigues. Guia para mediação do Museu a Céu Aberto da Ilha das Flores. FFP/UERJ/CMIIF: São Gonçalo, 2012. 28p. (mimeo)

5. CURY, Marília Xavier. Educação em Museus: Panoramas, Dilemas e Algumas Ponderações. Ensino Em Re-Vista, V.20, n. 1, p. 13-28, jan/jun. 2013. 
6. OLIVEIRA, Cecilia Helena de Salles. O tempo presente e os sentidos dos museus de história. Revista História Hoje, v. 2, nº 4, p. 103-123- 2013. 